\title{
Overexpression of the CYP51A1 Gene and Repeated Elements are Associated with Differential Sensitivity to DMI Fungicides in Venturia inaequalis
}

\author{
Sara M. Villani, Jon Hulvey, Jean-Michel Hily, and Kerik D. Cox
}

First author: Department of Plant Pathology, Mountain Horticultural Crops Research and Extension Center, North Carolina State University, Mills River 28759; second author: Biology Department, University of Massachusetts, Life Sciences Lab N585, Amherst 01003; third author: Institut National de la Recherche Agronomique, Université de Strasbourg, UMR 1131 santé de la Vigne et Qualité du Vin, Colmar Cedex, France; and fourth author: Section of Plant Pathology and Plant-Microbe Biology, School of Integrative Plant Science, Cornell University, Geneva, NY 14456.

Accepted for publication 26 January 2016.

\begin{abstract}
Villani, S. M., Hulvey, J., Hily, J-M., and Cox, K. D. 2016. Overexpression of the CYP51A1 gene and repeated elements are associated with differential sensitivity to DMI fungicides in Venturia inaequalis. Phytopathology 106:562-571.

The involvement of overexpression of the CYP51A1 gene in Venturia inaequalis was investigated for isolates exhibiting differential sensitivity to the triazole demethylation inhibitor (DMI) fungicides myclobutanil and difenoconazole. Relative expression (RE) of the CYP51A1 gene was significantly greater $(P<0.0001)$ for isolates with resistance to both fungicides $\left(\mathrm{M}_{\mathrm{R}} \mathrm{D}_{\mathrm{R}}\right.$ phenotype) or with resistance to difenoconazole only $\left(\mathrm{M}_{\mathrm{S}} \mathrm{D}_{\mathrm{R}}\right.$ phenotype $)$ compared with isolates that were resistant only to myclobutanil $\left(M_{R} D_{S}\right.$ phenotype) or sensitive to both fungicides $\left(M_{S} D_{S}\right.$ phenotype). An average of 9- and 13-fold increases in CYP51A1 RE were

observed in isolates resistant to difenoconazole compared with isolates with $M_{R} D_{S}$ and $M_{S} D_{S}$ phenotypes, respectively. Linear regression analysis between isolate relative growth on myclobutanil-amended medium and $\log _{10} \mathrm{RE}$ revealed that little to no variability in sensitivity to myclobutanil could be explained by CYP51A1 overexpression $\left(R^{2}=0.078\right)$. To investigate CYP51A1 upstream anomalies associated with CYP51A1 overexpression or resistance to difenoconazole, Illumina sequencing was conducted for three isolates with resistance to difenoconazole and one baseline isolate. A repeated element, "EL 3,1,2", with the properties of a transcriptional enhancer was identified two to four times upstream of CYP51A1 in difenoconazole-resistant isolates but was not found in isolates with the $M_{R} D_{S}$ phenotype. These results suggest that different mechanisms may govern resistance to different DMI fungicides in the triazole group.
\end{abstract}

Apple scab, caused by the fungal pathogen Venturia inaequalis (Cooke) G. Winter, is among the most prevalent and economically important diseases of apple in the northeastern United States (MacHardy 1996; MacHardy et al. 2001). In the United States, disease management relies on the application of multi- and single-site fungicides due to the paucity of apple cultivars that have both durable apple scab resistance and desired horticultural traits (Köller and Wilcox 2001; Lesniak et al. 2011; MacHardy 1996). Introduced in the 1980 s, the sterol demethylation inhibitors (DMI) are a class of broadspectrum, single-site fungicides that have consistently demonstrated high pre- and postinfection activity against a number of apple fungal pathogens, including V. inaequalis (Köller and Wilcox 1999; Szkolnik 1981; Villani et al. 2015), Podosphaera leucotricha (Yoder 2000), and Gymnosporangium juniper-virginianae (Yoder et al. 2014). Indeed, even 10 years after their introduction for use in commercial apple orchards in the United States, DMIs provided curative activity up to $96 \mathrm{~h}$ following infection by $V$. inaequalis (Beckerman et al. 2015).

The ability of DMI fungicides to arrest fungal growth during the infection process contributes to the success of this fungicide class as a potent curative fungicide. Specifically, DMI fungicides interrupt ergosterol biosynthesis by inhibiting demethylation at the 14- $\alpha$ carbon of lanosterol, a sterol intermediate of ergosterol, which is essential for hyphal growth (Köller and Scheinpflug 1987). This highly specific mode of action, in addition to their repetitive use as a postinfection fungicide, has gradually led to diminished efficacy and resistance in major apple production regions throughout the

Corresponding author: K. D. Cox; E-mail address: kdc33@cornell.edu

http://dx.doi.org/10.1094/PHYTO-10-15-0254-R

(C) 2016 The American Phytopathological Society
United States and Canada (Braun and McRae 1992; Hildebrand et al. 1988; Jobin and Carisse 2007; Köller et al. 1997; Villani and Cox 2011; Villani et al. 2015).

Unfortunately, growers have been increasingly reporting instances of suspected or confirmed resistance to older DMI fungicide products, including Rally 40WSP/Nova 40W (myclobutanil) and Rubigan/ Vintage SC (fenarimol). An extensive 10-year study on myclobutanil resistance in populations of $V$. inaequalis throughout the northeastern and mid-Atlantic United States concluded that $63 \%$ of the populations screened had practical resistance to the fungicide (Villani et al. 2015). During the same study, practical resistance to the more intrinsically active DMI fungicide, difenoconazole (Inspire), was not observed in any populations with confirmed resistance to myclobutanil (Villani et al. 2015). Although cross sensitivity within this class has historically been observed in other plant pathogens (Hsiang et al. 1997; Karaoglanidis and Thanassoulopoulos 2003), cross-sensitivity between myclobutanil and difenoconazole was only apparent in DMI-sensitive populations and not in DMI-resistant populations of $V$. inaequalis from New York. This lack of cross-sensitivity between myclobutanil and difenoconazole in a population with practical resistance to myclobutanil suggests that different genetic mechanisms may be involved in resistance against the two fungicides (Hawkins et al. 2011; Villani et al. 2015).

The molecular basis of resistance to the DMI fungicides has been extensively studied in both human and plant fungal pathogens, including V. inaequalis (Cools et al. 2013; Hamamoto et al. 2000; Hulvey et al. 2012; Luo and Schnabel 2008; Lupetti et al. 2002; Ma et al. 2006; Schnabel and Jones 2001). The more common mechanisms of resistance include (i) missense mutations within the target CYP51A1 gene (Asai et al. 1999; Becher and Wirsel 2012; Délye et al. 1997; Stammler et al. 2009) reducing the binding affinity of 
DMI fungicides, (ii) overexpression of energy-dependent ABC and MFS transporters encoding drug efflux pumps (Hayashi et al. 2002; Hulvey et al. 2012; Nakaune et al. 1998), and (iii) overexpression of the CYP51A1 gene (Hamamoto et al. 2000; Ma et al. 2006; Schnabel and Jones 2001). Overexpression of the CYP51A1 gene in phytopathogenic fungi has been attributed to insertions and repeated elements acting as transcriptional enhancers or to gene duplications increasing the copy number of the CYP51A1 gene (Hawkins et al. 2011). In isolates of $V$. inaequalis from Michigan, overexpression of CYP51A1 has been previously determined to be a mechanism of resistance to myclobutanil (Schnabel and Jones 2001). An insertion of 553 bp upstream of the CYP51A1 gene was found to contain three predicted promoters and coincided with higher expression values in myclobutanil-resistant isolates. This insertion was not always present in myclobutanil-resistant or high-expressing isolates, and overexpression of CYP51A1 was not always present in isolates resistant to myclobutanil, indicating that other mechanisms could be responsible for resistance to that fungicide.

The widespread adaptation of difenoconazole into apple scab management programs in conjunction with a lack of cross-sensitivity between myclobutanil and difenoconazole in isolates resistant to myclobutanil (Villani et al. 2015) prompted us to reexamine the role of CYP51A1 in DMI fungicide resistance and determine whether different molecular mechanisms for resistance were present. Specifically, our objectives were to (i) evaluate the relative expression (RE) of the $V$. inaequalis CYP51Al gene and the presence of mutations within the coding sequence of the CYP51Al gene for isolates with varying sensitivity phenotypes to myclobutanil and difenoconazole and (ii) conduct traditional Sanger sequencing and Illumina sequencing with de novo assembly to identify upstream anomalies associated with CYP51A1 overexpression or resistance to either DMI fungicide.

\section{MATERIALS AND METHODS}

Collection of $V$. inaequalis isolates. The contribution of the CYP51A1 gene in resistance to the DMI fungicides myclobutanil or difenoconazole was evaluated for 50 isolates. Isolates were selected during the 2010 and 2011 seasons from four research and commercial apple orchards located in western New York, Maine, and West Virginia, and two western New York baseline orchards. According to records submitted by growers and research personnel, there were no fewer than 20 historical DMI fungicide applications in the research and commercial orchards surveyed for this study. Isolates collected from baseline orchards were never exposed to any single-site fungicide classes, including anilinopyrimidines, benzimidazoles, DMIs, guanidines, quinone outside inhibitors (QoI), or succinate dehydrogenase inhibitors.

All isolates selected for this study were obtained from sporulating apple scab lesions originating from infections on young, fully expanded leaves. Each single clonal conidial lesion isolate was phenotyped for sensitivity to the DMI fungicides myclobutanil and difenoconazole using microscopy-aided mycelial relative growth assays, as previously described and validated (Frederick et al. 2014; Köller et al. 2004; Villani et al. 2015). Briefly, individual sporulating clonal conidial lesions (Köller et al. 2004) were removed using a sterile cork borer $(5 \mathrm{~mm}$ in diameter), placed in $1.2 \mathrm{ml}$ of sterile distilled water, and shaken for $60 \mathrm{~s}$ to dislodge conidia from the lesion. The leaf discs were promptly removed and $100-\mu 1$ suspensions of $10^{3}$ to $10^{4} \mathrm{~V}$. inaequalis conidia $\mathrm{ml}^{-1}$ were evenly distributed on potato dextrose agar (PDA; Difco Laboratories) amended with streptomycin sulfate $\left(50 \mu \mathrm{g} \mathrm{ml}^{-1}\right)$, chloramphenicol $\left(50 \mu \mathrm{g} \mathrm{ml}^{-1}\right)$, and either analytical grade myclobutanil or difenoconazole (SigmaAldrich) dissolved in acetone (Sigma-Aldrich) at a discriminatory dose of $0.1 \mu \mathrm{g} \mathrm{ml}^{-1}$ (Villani et al. 2015) or no fungicide. Singleconidial lesion isolates were incubated at $22^{\circ} \mathrm{C}$ for 6 days, and mycelial growth of five randomly selected microcolonies originating from single spores was determined by measuring microcolony diameter or germ tube length (for spores with greatly inhibited growth) using a SPOT Idea digital camera with the SPOT Imaging Basic software package (Diagnostic Instruments Inc.) attached to an Olympus SZX12 stereoscope (Olympus America Inc.). The in vitro sensitivity response for each single conidial isolate was expressed as mean percent relative growth (\%RG), as previously described (Frederick et al. 2014; Smith et al. 1991; Villani et al. 2015).

Each clonal conidial lesion isolate was characterized as being sensitive to or having practical resistance to myclobutanil or difenoconazole based on previously validated thresholds for practical resistance (Villani et al. 2015). Isolates that had RG values greater than $60 \%$ on either myclobutanil- or difenoconazoleamended medium were characterized as resistant to the respective fungicide, whereas any isolate with RG values less than $60 \%$ on either DMI-amended medium was considered sensitive because labeled rates of Rally 40WSP or Inspire (difenoconazole) could still effectively control isolates with such phenotypes under field conditions (Villani et al. 2015).

Extraction of RNA. From each isolate, a single conidium was selected and grown on PDA in either the presence or absence of a DMI fungicide. To maintain phenotypes with varying sensitivities to DMI, isolates with practical resistance $(\mathrm{RG}>60 \%)$ to myclobutanil, difenoconazole, or both DMI fungicides were maintained on PDA amended with a low concentration $\left(0.01 \mu \mathrm{g} \mathrm{ml}^{-1}\right)$ of myclobutanil, difenoconazole, or both fungicides, respectively. Alternatively, isolates sensitive to both DMI fungicides were maintained on PDA in the absence of either fungicide. Following 8 weeks of incubation at $22^{\circ} \mathrm{C}, 50$ to $100 \mathrm{mg}$ of mycelium was harvested from the agar surface and ground in liquid nitrogen using a sterile mortar and pestle. Total RNA was extracted from the 50 isolates using the Omega Bio-Tek E.Z.N.A. Plant RNA Kit (Omega Bio-Tek). DNA was removed with the TURBO DNA-free Kit (Ambion by Life Technologies). For all isolates, RNA was standardized to a concentration of $5 \mathrm{ng} \mathrm{ml}^{-1}$ prior to expression analysis of the CYP51Al gene.

cDNA synthesis and reverse-transcription quantitative polymerase chain reaction. Reverse-transcription quantitative polymerase chain reaction (RT-qPCR) was used to determine the $\mathrm{RE}$ of the CYP51A1 gene for the 50 selected isolates. The iScript One-Step RT-PCR with SYBR Green Kit (Bio-Rad Laboratories Inc.) utilizing the SYBR Green I reporter dye was used for firststrand DNA synthesis and all subsequent RT-qPCR. To normalize the concentration of RNA, a 162-bp fragment of the $V$. inaequalis actin housekeeping gene (accession number AF269254) (Schnabel and Jones 2001) was amplified with primers ViActin-F and ViActin-R (Table 1). Primers ViCyp51-F and ViCyp51-R (Table 1) were designed to amplify a 161-bp region within the CYP51A1 gene (accession number AF227916). Reactions were carried out in $25-\mu$ l volumes and contained $12.5 \mu \mathrm{l}$ of $2 \times$ SYBR Green RT-PCR mix (final concentration $1 \times), 300 \mathrm{nM}$ each primer, $0.5 \mu \mathrm{l}$ of iScript RT for onestep RT-PCR, and $12.5 \mathrm{ng}$ of RNA. Amplifications were performed in a Bio-Rad CFX96 Real-Time PCR Detection System (Bio-Rad Laboratories Inc.) with the following parameters: $10 \mathrm{~min}$ at $50^{\circ} \mathrm{C}$, $5 \mathrm{~min}$ at $95^{\circ} \mathrm{C}$, followed by 40 cycles of $10 \mathrm{~s}$ at $95^{\circ} \mathrm{C}$ and $30 \mathrm{~s}$ at $57^{\circ} \mathrm{C}$. For each isolate, three technical replicates were included and the experiment was repeated. A final melt curve analysis was also included to ensure proper amplification of a single amplicon. For three isolates (baseline, myclobutanil-resistant/difenoconazole-sensitive $\left[\mathrm{M}_{\mathrm{R}} \mathrm{D}_{\mathrm{S}}\right]$, and myclobutanil-sensitive/difenoconazole-resistant $\left[\mathrm{M}_{\mathrm{S}} \mathrm{D}_{\mathrm{R}}\right]$ ), induced expression of the CYP51Al gene was evaluated by applying a mixture of myclobutanil and difenoconazole at their maximum labeled field rates of $333 \mathrm{~g} \mathrm{ha}^{-1}$ and $293 \mathrm{ml} \mathrm{ha}^{-1}$, respectively, using an airbrush sprayer (Aztek 320A; Testor). The fungicides were applied for $5 \mathrm{~s}$ over two $\mathrm{V}$. inaequalis colonies (approximately $40 \mathrm{~mm}$ in diameter) and RNA was extracted $24 \mathrm{~h}$ following application.

The comparative threshold cycle $\left(\mathrm{C}_{\mathrm{T}}\right)$ method (Livak and Schmittgen 2001) was used to determine CYP51A1 expression of test isolates relative to the expression of calibrator isolate 26A-22-11, the isolate with the greatest mean difference in $\mathrm{C}_{\mathrm{T}}$ values between $C Y P 51 A 1$ and the actin gene $\left(\Delta \mathrm{C}_{\mathrm{T}}\right)$ (Hulvey et al. 2012; Schnabel and Jones 
2001) and, thus, the lowest RE of CYP51A1. Data were calibrated by determining the difference in $\Delta \mathrm{C}_{\mathrm{T}}$ values between the test isolate and the calibrator isolate $\left(\Delta \Delta \mathrm{C}_{\mathrm{T}}\right)$, and $\mathrm{RE}$ of the CYP51A1 gene for each isolate was calculated using the formula $2^{-\Delta \Delta C T}$, as described previously (Livak and Schmittgen 2001; Schnabel and Jones 2001). A validation experiment was performed with dilutions of the calibrator isolate prior to utilizing the $\mathrm{C}_{\mathrm{T}}$ method, to ensure that the efficiency of both CYP51A1 amplification and actin amplification were approximately equal (slope $=0.01)$.

The effect of CYP51A1 RE on DMI sensitivity phenotype (resistance to neither, both, or one DMI fungicide) was determined using the generalized linear mixed models with the GLIMMIX procedure of SAS (version 9.4; SAS Institute Inc.). Differences in RE of isolates exhibiting different sensitivity phenotypes was determined using the lsmeans statement of GLIMMIX at the 5\% level of significance. Simple linear regression analysis was conducted to determine the relationship between isolate relative growth for each fungicide and mean RE ( $\log _{10}$ transformed) (SigmaPlot version 11.0; Systat Software Inc.).

Extraction of genomic DNA. Prior to extraction of genomic DNA (gDNA), isolates were grown and maintained in a manner identical to that described above for RNA extraction. Following 8 weeks of incubation at $22^{\circ} \mathrm{C}, 50$ to $100 \mathrm{mg}$ of mycelium from each isolate was harvested from the growth medium and ground in liquid nitrogen using a sterile mortar and pestle. Extraction of gDNA was accomplished using the Omega Bio-Tek E.Z.N.A. Plant DNA Kit (Omega Bio-Tek) in accordance with the manufacturer's instructions.

PCR amplification of the CYP51A1 gene in $V$. inaequalis. In order to determine whether mutations altering the coding sequence of the $C Y P 51 A 1$ gene were present in isolates resistant to the DMI fungicide difenoconazole, the entire CYP51Al gene in $V$. inaequalis was sequenced for 15 isolates representing different difenoconazole sensitivity phenotypes. Primers were designed to amplify the CYP51Al gene based on the sequence of $V$. inaequalis isolate Ent23 (accession number AF227916) (Schnabel and Jones 2001). Using the primer sets SVcyp-38-F/SVcyp400-R, SVcyp300-
F/SVcyp1200-R, and SVcyp1080-F/SVcyp1720-R (Table 1), the 1,674-bp CYP51A1 gene was amplified for three baseline isolates (3a-27-10, 3a-19-10, and 4a-45-10), three $\mathrm{M}_{\mathrm{S}} \mathrm{D}_{\mathrm{S}}$ isolates (26a-4511, 1a-31-10, and 42a-30-10), three $\mathrm{M}_{R} \mathrm{D}_{\mathrm{R}}$ isolates (38b-45-11, 40b33-11, and 7a-27-10), an $\mathrm{M}_{S} \mathrm{D}_{\mathrm{R}}$ isolate (40b-40-11, 42a-2-11, and 42a-10-11), and three $\mathrm{M}_{\mathrm{R}} \mathrm{D}_{\mathrm{S}}$ isolates (40b-28-11, 45b-33-11, and 7a-1$10)$. For each primer set, PCR was performed in $25-\mu \mathrm{l}$ reaction volumes and contained $1 \times$ PCR buffer, $0.4 \mu \mathrm{M}$ each primer, $2.5 \mathrm{mM}$ $\mathrm{MgCl}_{2}, 200 \mu \mathrm{M}$ each dNTP, $0.625 \mathrm{U}$ of GoTaq Flexi DNA Polymerase (Promega Corp.) and 5 to $10 \mathrm{ng}$ of gDNA. All amplifications were performed in a T100 Thermal Cycler (Bio-Rad Laboratories Inc.) with the following program: 2 min at $94^{\circ} \mathrm{C} ; 30$ cycles of $30 \mathrm{~s}$ at $94^{\circ} \mathrm{C}, 30 \mathrm{~s}$ at $50^{\circ} \mathrm{C}$, and $1 \mathrm{~min}$ at $72^{\circ} \mathrm{C}$; followed by a final extension of $10 \mathrm{~min}$ at $72^{\circ} \mathrm{C}$.

PCR products were separated on a $2 \%$ agarose gel (Bio-Rad Laboratories Inc.) stained with ethidium bromide in $1 \times$ Trisacetate-EDTA buffer at $100 \mathrm{~V}$ for $1 \mathrm{~h}$. Photographs of the gel were taken on a KODAK Gel Logic 200 Imaging System (Eastman Kodak Company). Using the QiaQuick PCR Purification Kit (Qiagen), PCR products were purified and sequenced with internal primers in both directions for each primer set (Table 1) using an Applied BioSystems Automated 3730xl DNA Analyzer at the Cornell University DNA sequencing facility in Ithaca, NY. For each isolate, sequences of CYP51A1 were assembled with using CLC Main Workbench (version 6.8.2; CLCBio). After removing two introns previously characterized by Schnabel and Jones (2001), the resulting sequences were translated and aligned to identify any anomalies in amino acid sequence among the isolates.

Cloning of the CYP51A1 upstream promoter region. To obtain the gDNA sequence upstream of the $V$. inaequalis CYP51A1 coding region, 5' rapid amplification of genomic ends (RAGE) was carried out on baseline isolate $3 \mathrm{a}-27-10$ in accordance with Liu and Baird (2001). Following the addition of a poly(C) tail with terminal transferase, PCR was performed using primer Vicyp22R (Table 1), which was designed to anneal to the $5^{\prime}$ end of the $V$. inaequalis CYP51A1 coding region, and a selective anchored

TABLE 1. Oligonucleotide primers used in this study and description of their amplification target

\begin{tabular}{|c|c|c|}
\hline Primer & Sequence $\left(5^{\prime}\right.$ to $\left.3^{\prime}\right)$ & Amplification targets ${ }^{a}$ \\
\hline ViActin-F & GAT GGA GCA AAA GAA GTT CGT CA & qPCR primers for determining the expression level of the actin gene \\
\hline ViActin-R & GAA TTG AGG GTA GCG TTT GGT ATA G & in Venturia inaequalis \\
\hline ViCyp51-F & GAT GGA GCA AAA GAA GTT CGT CA & qPCR primers for determining the expression level of the CYP51A1 \\
\hline ViCyp51-R & GAA TTG AGG GTA GCG TTT GGT ATA G & gene in $V$. inaequalis \\
\hline Vicyp22R & GCA AAG GAG AGA GGA GTC CCA T & Primers used during RAGE cloning to elucidate the far \\
\hline Vicyp11R & AGG AGT CCC ATT GTT GGT GGT GAG & upstream/promoter region of the CYP51A1 gene in $V$. inaequalis \\
\hline AJ468F & ATC CCT GAA TTT GAG AGC ACT & Amplification of the region -290 to +578 relative to the CYP51A1 \\
\hline SV395R & ACA TAG GAT TTG AGA GCT TCG GTG GTG AGA C & upstream sequence of $V$. inaequalis isolate $3 a-27-10$ \\
\hline AJ414 & TGC CAA GAA GAA TGA AGG TAA A & $\begin{array}{l}\text { Sequencing of the PCR product generated by primers AJ468F and } \\
\text { SV395R }\end{array}$ \\
\hline Vi23F & GAA ACC TAG GTG CAA GAG CAA & Amplification of the region -738 to -134 relative to the CYP51A1 \\
\hline Vi-134R & TTA CCC TGG CCC TGG CTT TGG CTT T & upstream sequence of $V$. inaequalis isolate $3 a-27-10$ \\
\hline VI-185R & TGG CAT GGC CCA CCA ATC ACA TGC T & $\begin{array}{l}\text { Sequencing of the PCR product generated by primers Vi23F and } \\
\text { Vi-134R }\end{array}$ \\
\hline SVcyp-38-F & ATA CAG ACG AGC AAC ACC ACA CT & Amplification of the region -38 to +400 relative to the first $5^{\prime}$ \\
\hline SVcyp400-R & TCC TCT GCG TTG ACA TGG CTC T & adenosine of $C Y P 51 A 1$ \\
\hline SVcyp300-F & TTT ACC TTC ATT CTT CTT GGC A & Amplification of the region +300 to $+1,200$ relative to the first $5^{\prime}$ \\
\hline SVcyp1200-R & ATG CAT GCG AAG AGT TTC TTT G & adenosine of CYP51A1 \\
\hline SVcyp1080-F & GGA AGA ACT ATA CCA AGA ACA A & Amplification of the region $+1,080$ to $+1,720$ relative to the first $5^{\prime}$ \\
\hline SVcyp1720-R & TCC CAG GCT GTT CAC CAA ACG T & adenosine of $C Y P 51 A 1$ \\
\hline seqSVcyp160-F & CAC TGG TTT CCC TTC TTC GGC A & Sequencing of the PCR product generated by primers SVcyp-38-F \\
\hline seqSVcyp260-R & TTG CAT TCT CAT TGT CGC ATT AC & and SVcyp400-R \\
\hline seqSVcyp620-F & ACC CTC AAT TCA AAG GCG AAA & Sequencing of the PCR product generated by primers SVcyp300-F \\
\hline seqSVcyp720-R & AAC CTC CTT GCC TTG TAG TGA G & and SVcyp1200-R \\
\hline seqSVcyp $1340-\mathrm{F}$ & AGA AGT GGG AGC CTC ACC GTT G & Sequencing of the PCR product generated by primers SVcyp $1080-\mathrm{F}$ \\
\hline seqSVcyp1440-R & GAG TCC ATA GCC GTA ATC CTC T & and SVcyp1720-R \\
\hline EL3,1-for & TGA GCC GTG TCC GAG GTG AGT C & Amplification of EL 3,1,2 in immediate $C Y P 51 A 1$ upstream region \\
\hline VI-185F & AGC ATG TGA TTG GTG GGC C & Amplification of EL $3,1,2$ in $\mathrm{Vi}-134^{+59}$ to 228 CYP51A1 upstream \\
\hline 7535hiup-R & GTC GGT GGT AGA CTC ACC ACC AT & region \\
\hline
\end{tabular}

${ }^{\mathrm{a}} \mathrm{qPCR}=$ quantitative polymerase chain reaction and RAGE $=$ rapid amplification of genomic ends. 
primer complimentary to the cytosine tail (Liu and Baird 2001). To improve specificity and improve DNA concentration, PCR using the product from the first reaction was conducted with universal amplification primer (Liu and Baird 2001) and Vicyp11R (Table 1). The purified product was cloned into PGEM-Teasy (Promega Corp.) according to the manufacturer's instructions, and 10 clones were subjected to Sanger sequencing, as described above.

Amplification and sequencing of the CYP51A1 upstream promoter region for DMI-resistant isolates of $\mathrm{V}$. inaequalis. To determine putative upstream anomalies associated with resistance to difenoconazole or myclobutanil, PCR and Sanger sequencing were conducted for all 50 isolates of $V$. inaequalis with varying sensitivity to the two fungicides. Based on the upstream sequences obtained by RAGE and subsequent cloning, primer set Vi23F and Vi-134R (Table 1) was designed and used to amplify the region -738 to -135 bp upstream of the $V$. inaequalis CYP51Al gene (relative to baseline isolate $3 \mathrm{a}-27-10)$. PCR was performed in $25-\mu \mathrm{l}$ volumes as described above. Amplifications were performed in a T100 Thermal Cycler (Bio-Rad Laboratories Inc.) with the following program: $2 \mathrm{~min}$ at $94^{\circ} \mathrm{C} ; 30$ cycles of $30 \mathrm{~s}$ at $94^{\circ} \mathrm{C}, 30 \mathrm{~s}$ at $56^{\circ} \mathrm{C}$, and $60 \mathrm{~s}$ at $68^{\circ} \mathrm{C}$; followed by a final extension of $7 \mathrm{~min}$ at $68^{\circ} \mathrm{C}$. PCR products were separated on a $2 \%$ agarose gel (Bio-Rad Laboratories Inc.) stained with ethidium bromide in $1 \times$ Tris-acetate-EDTA buffer at $100 \mathrm{~V}$ for $1 \mathrm{~h}$. Photographs of the gel were taken on a KODAK Gel Logic 200 Imaging System (Eastman Kodak Company). PCR products were purified and sequenced as described above using primer Vi-185R (Table 1).

To determine the presence of anomalies in the region immediately upstream of the CYP51A1 gene not amplified by Vi23F and Vi-134R (i.e., -134 to the first $5^{\prime}$ adenine relative to the start), PCR was performed using primers AJ468F (Schnabel and Jones 2001) and SV395R (Table 1). PCR was performed in $25-\mu$ l volumes as described above. Amplifications were performed in a T100 Thermal Cycler (Bio-Rad Laboratories Inc.) using the following program: $2 \mathrm{~min}$ at $94^{\circ} \mathrm{C} ; 35$ cycles of $30 \mathrm{~s}$ at $94^{\circ} \mathrm{C}, 45 \mathrm{~s}$ at $53^{\circ} \mathrm{C}$, and $2 \mathrm{~min}$ at $72^{\circ} \mathrm{C}$; followed by a final extension of $7 \mathrm{~min}$ at $72^{\circ} \mathrm{C}$. PCR products were separated on a $1 \%$ agarose gel (Bio-Rad Laboratories Inc.) stained with ethidium bromide in $1 \times$ Tris-acetate-EDTA buffer at $100 \mathrm{~V}$ for 1 h. Photographs of the gel were taken on a KODAK Gel Logic 200 Imaging System (Eastman Kodak Company). PCR products were purified and sequenced as described above using primer AJ414 (Schnabel and Jones 2001) (Table 1).

Upstream sequence assembly and prediction of promoter elements. For isolates in which upstream fragments were successfully amplified for both sets of primers (Vi23F and Vi-134R; AJ468F and SV395R), assembly and alignments were made using CLC Main Workbench (version 6.8.2; CLCBio). For all isolates, the prediction of promoter elements within the upstream sequence of $C Y P 51 A 1$ was carried out using the Berkeley Drosophila Genome Project's Neural Network Promoter Prediction software, with a standard cutoff score of 0.8 .

Illumina sequencing, de novo assembly, and annotation of CYP51A1 upstream sequences. Illumina sequencing was conducted to elucidate the upstream region of CYP51A1 for three isolates in which no fragment was generated with primer pair AJ468F/SV395R. Illumina sequencing of isolates 40b-40-11 $\left(\mathrm{M}_{S} \mathrm{D}_{\mathrm{R}}\right)$, 41b-14-11 $\left(\mathrm{M}_{\mathrm{S}} \mathrm{D}_{\mathrm{R}}\right)$, and 43b-40-11 $\left(\mathrm{M}_{\mathrm{R}} \mathrm{D}_{\mathrm{R}}\right)$ was accomplished using the Illumina MiSeq v3 600bp kit. Additionally, a baseline isolate, 3a-27-10, in which the 738-bp upstream sequence of CYP51A1 had already been assembled using PCR and Sanger sequencing, was included for comparison. gDNA from each of the four isolates was extracted using the Omega Bio-Tek E.Z.N.A. Plant DNA Kit, as previously described. Sample preparation, including library construction, was completed at the Cornell University Genomic Facility using the TruSeq DNA Library Prep Kit (Illumina). Digital PCR was performed at the Cornell University Genomic Facility on all samples to ensure optimum DNA loading for proper clustering on the Illumina sequencer. A single MiSeq run with 300-bp paired- end reads was performed on the four pooled isolate samples expected to provide $15 \mathrm{~GB}$ of sequence data. After sequencing, low-quality Illumina MiSeq data were filtered and raw reads were assembled for each isolate using CLC Genomics Workbench with default settings (version 8.0.1; CLC Bio). Additional assembles were also made on the combined read data from the three difenoconazole-resistant isolates to maximize coverage of the CYP51A1 upstream region.

\section{RESULTS}

DMI fungicide sensitivity and expression of the CYP51AI gene. DMI fungicide sensitivity and expression of the $V$. inaequalis CYP51A1 gene was evaluated for 50 isolates that were collected from six orchard populations in 2010 and 2011. The mean \%RG of isolates on medium amended with a discriminatory concentration of myclobutanil and difenoconazole ranged from 0 to 131.2 and 0 to $138.3 \%$, respectively. Mean RE of the CYP51Al gene using the comparative $\mathrm{C}_{\mathrm{T}}$ method ranged from 1.00 to 179.21 , with the calibrator isolate, 26A-22-11, and an isolate resistant to difenoconazole, 7a-48-10, having the lowest and highest RE, respectively (Table 2). Application of difenoconazole or myclobutanil to mature colonies of three $V$. inaequalis isolates $24 \mathrm{~h}$ prior to RNA extraction in an attempt to induce target gene expression did not affect the level of CYP51A1 RE compared with copies of the isolates that did not receive the fungicide application prior to extraction (data not shown). Hence, only noninduced RE was determined for the remaining isolates. Isolates resistant to difenoconazole $(n=23)$ had a mean $C Y P 51 A 1 \mathrm{RE}$ of $45.91 \pm 8.3$, which was significantly higher $(P<0.0001)$ than for isolates sensitive to difenoconazole (mean $\mathrm{RE}=4.19 \pm 0.6 ; n=27)$. For isolates resistant to myclobutanil $(n=24)$, mean CYP51A1 RE was slightly greater than for isolates sensitive to myclobutanil ( $n=26$; mean $27.68 \pm 5.9$ compared with $19.08 \pm 7.6)$ but these differences were not significant $(P=0.275)$.

To understand the extent of the contribution of CYP51A1 expression in resistance to myclobutanil and difenoconazole, linear regression analysis of isolate mean $\% \mathrm{RG}$ on difenoconazole- or myclobutanil-amended medium and $\log _{10}$ RE values was performed. The regression analysis revealed significant relationships between isolate \%RG on either difenoconazole- or myclobutanilamended medium and $\log _{10} \operatorname{RE}(P \leq 0.0001$ and $P=0.0489$, respectively). However, although CYP51A1 expression explained some of the variability in isolate sensitivity to difenoconazole $\left(R^{2}=\right.$ $0.630)$ (Fig. 1A), little to none of the variability in isolate sensitivity to myclobutanil could be explained by CYP51A1 RE $\left(R^{2}=0.078\right)$ (Fig. 1B).

In order to gain further insight into the role of CYP51A1 overexpression in difenoconazole resistance or myclobutanil resistance, isolates were further characterized into four groups based on their in vitro sensitivity to myclobutanil and difenoconazole. Of the 50 isolates evaluated in this study, 15 were resistant to myclobutanil and difenoconazole $\left(\mathrm{M}_{\mathrm{R}} \mathrm{D}_{\mathrm{R}}\right)$, nine were resistant to myclobutanil but sensitive to difenoconazole $\left(\mathrm{M}_{R} \mathrm{D}_{\mathrm{S}}\right)$, eight were sensitive to myclobutanil but resistant to difenoconazole $\left(\mathrm{M}_{S} \mathrm{D}_{\mathrm{R}}\right)$, and 18 were sensitive to both fungicides $\left(\mathrm{M}_{\mathrm{S}} \mathrm{D}_{\mathrm{S}}\right)$ (Table 2). For isolates resistant to difenoconazole $\left(\mathrm{M}_{\mathrm{R}} \mathrm{D}_{\mathrm{R}}\right.$ and $\left.\mathrm{M}_{\mathrm{S}} \mathrm{D}_{\mathrm{R}}\right) \mathrm{RE}$ was significantly greater $(P \leq 0.0001)$ compared with isolates sensitive to myclobutanil. Conversely, when the difenoconazole sensitivity classification remained constant (i.e., $\mathrm{M}_{\mathrm{R}} \mathrm{D}_{\mathrm{S}}$ versus $\mathrm{M}_{\mathrm{S}} \mathrm{D}_{\mathrm{S}}$ ), no significant differences in $\mathrm{RE}$ of CYP51A1 were observed between isolates resistant or sensitive to myclobutanil (Fig. 2).

PCR amplification of the CYP51A1 gene in $V$. inaequalis. The 1,674-bp CYP51A1 gene was sequenced for 15 isolates: 3 representative isolates from each of the four DMI-sensitivity classifications and 3 baseline isolates. The sequence of the CYP51A1 gene for the 15 isolates had $100 \%$ identity to $\mathrm{V}$. inaequalis isolate Ent54 (accession number AF262756). Following identification of two previously characterized introns (Schnabel and Jones 
2001), translation revealed no missense mutations in the coding region of the gene (data not shown).

Cloning of the CYP51A1 upstream promoter region. 5' RAGE was used to clone the upstream region of the $V$. inaequalis CYP51A1 gene for baseline isolate 3a-27-10 (GenBank accession number KT694303). A 738-bp region was isolated upstream of the CYP51A1 open reading frame and had $99 \%$ nucleotide identity to the upstream region of $V$. inaequalis isolate Ent23 (accession number AF227916) (Schnabel and Jones 2001). A novel 387-bp region of DNA was discovered in the region directly upstream of the previously characterized upstream region of the $V$. inaequalis CYP51A1 gene (Schnabel and Jones 2001). Given that none of the previously described upstream insertions (Schnabel and Jones 2001) were detected in the upstream region of the baseline isolate, all insertions or deletions in the promoter region of CYP51Al will be presented in the context of isolate 3a-27-10 unless otherwise noted.

Amplification of the region -738 to -135 bp upstream of the CYP51A1 gene was accomplished using primer set Vi23F and Vi-134R and yielded fragments of 593, 604, 797, 828 or 1,103 bp.

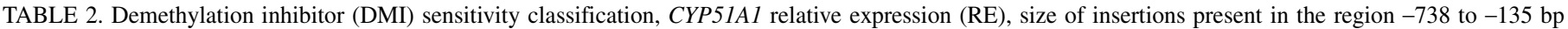

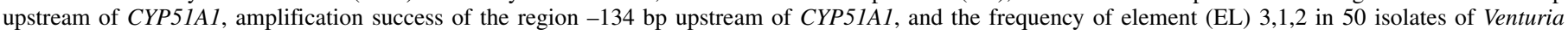
inaequalis with differing sensitivity to the DMI fungicides myclobutanil and difenoconazole

\begin{tabular}{|c|c|c|c|c|c|}
\hline Isolate & $\begin{array}{l}\text { DMI sensitivity } \\
\text { classification }^{\mathrm{a}}\end{array}$ & $C Y P 51 A 1 \mathrm{RE}^{\mathrm{b}}$ & $\begin{array}{c}\text { Insertion size } \\
(\mathrm{Vi} 23 \mathrm{~F} / \mathrm{Vi}-134 \mathrm{R})^{\mathrm{c}}\end{array}$ & $\begin{array}{l}\text { Amplification with } \\
\text { AJ468-F/SV395RC }\end{array}$ & $\begin{array}{l}\text { Frequency of EL } 3,1,2 \text { in } \\
C Y P 51 A 1 \text { promoter region }\end{array}$ \\
\hline $38 b-45-11$ & $\mathrm{M}_{\mathrm{R}} \mathrm{D}_{\mathrm{R}}$ & 34.53 & 0 & - & 2 \\
\hline $38 b-24-11$ & $\mathrm{M}_{\mathrm{R}} \mathrm{D}_{\mathrm{R}}$ & 38.05 & 0 & - & 2 \\
\hline $40 a-35-11$ & $\mathrm{M}_{\mathrm{R}} \mathrm{D}_{\mathrm{R}}$ & 36.00 & 0 & - & 2 \\
\hline $40 a-45-11$ & $\mathrm{M}_{\mathrm{R}} \mathrm{D}_{\mathrm{R}}$ & 41.64 & 0 & - & 2 \\
\hline $40 b-25-11$ & $\mathrm{M}_{\mathrm{R}} \mathrm{D}_{\mathrm{R}}$ & 5.77 & 0 & - & 4 \\
\hline $40 \mathrm{~b}-33-11$ & $\mathrm{M}_{\mathrm{R}} \mathrm{D}_{\mathrm{R}}$ & 5.46 & 499 & + & 0 \\
\hline $40 b-7-11$ & $\mathrm{M}_{\mathrm{R}} \mathrm{D}_{\mathrm{R}}$ & 100.42 & 0 & - & 2 \\
\hline $41 a-37-11$ & $M_{R} D_{R}$ & 53.94 & 0 & - & 2 \\
\hline $41 b-37-11$ & $\mathrm{M}_{\mathrm{R}} \mathrm{D}_{\mathrm{R}}$ & 71.50 & 0 & - & 2 \\
\hline $42 a-1-11$ & $\mathrm{M}_{\mathrm{R}} \mathrm{D}_{\mathrm{R}}$ & 36.25 & 0 & - & 2 \\
\hline $43 b-40-11$ & $\mathrm{M}_{\mathrm{R}} \mathrm{D}_{\mathrm{R}}$ & 20.39 & 0 & - & 2 \\
\hline $45 b-24-11$ & $\mathrm{M}_{\mathrm{R}} \mathrm{D}_{\mathrm{R}}$ & 6.10 & 0 & - & 2 \\
\hline $7 a-15-10$ & $M_{R} D_{R}$ & 105.73 & 0 & - & 2 \\
\hline $7 a-27-10$ & $\mathrm{M}_{\mathrm{R}} \mathrm{D}_{\mathrm{R}}$ & 25.16 & 0 & + & 0 \\
\hline $7 a-7-10$ & $\mathrm{M}_{\mathrm{R}} \mathrm{D}_{\mathrm{R}}$ & 35.22 & 0 & - & 2 \\
\hline $40 b-40-11$ & $\mathrm{M}_{\mathrm{S}} \mathrm{D}_{\mathrm{R}}$ & 27.28 & 0 & - & 2 \\
\hline 41b-14-11 & $\mathrm{M}_{\mathrm{S}} \mathrm{D}_{\mathrm{R}}$ & 64.44 & 0 & - & 2 \\
\hline $41 b-36-11$ & $\mathrm{M}_{\mathrm{S}} \mathrm{D}_{\mathrm{R}}$ & 58.89 & 0 & - & 2 \\
\hline $42 a-10-11$ & $\mathrm{M}_{\mathrm{S}} \mathrm{D}_{\mathrm{R}}$ & 23.10 & 0 & + & 0 \\
\hline $42 a-2-11$ & $\mathrm{M}_{\mathrm{S}} \mathrm{D}_{\mathrm{R}}$ & 42.51 & 0 & + & 0 \\
\hline $42 a-40-11$ & $\mathrm{M}_{\mathrm{S}} \mathrm{D}_{\mathrm{R}}$ & 2.65 & 0 & - & 4 \\
\hline $45 b-4-11$ & $M_{S} D_{R}$ & 40.78 & 0 & - & 2 \\
\hline $7 a-48-11$ & $M_{S} D_{R}$ & 179.21 & 0 & - & 2 \\
\hline $40 b-28-11$ & $\mathrm{M}_{\mathrm{R}} \mathrm{D}_{\mathrm{S}}$ & 2.39 & 352 & + & 0 \\
\hline $7 a-1-10$ & $\mathrm{M}_{\mathrm{R}} \mathrm{D}_{\mathrm{S}}$ & 8.90 & 0 & + & 0 \\
\hline $7 a-4-10$ & $\mathrm{M}_{\mathrm{R}} \mathrm{D}_{\mathrm{S}}$ & 3.00 & 0 & - & 0 \\
\hline $45 b-33-11$ & $\mathrm{M}_{\mathrm{S}} \mathrm{D}_{\mathrm{S}}$ & 11.23 & 0 & + & 0 \\
\hline $43 a-20-11$ & $\mathrm{M}_{\mathrm{S}} \mathrm{D}_{\mathrm{S}}$ & 8.75 & 0 & + & 0 \\
\hline $44 a-23-11$ & $\mathrm{M}_{\mathrm{S}} \mathrm{D}_{\mathrm{S}}$ & 4.82 & 0 & + & 0 \\
\hline $42 a-30-11$ & $\mathrm{M}_{\mathrm{S}} \mathrm{D}_{\mathrm{S}}$ & 9.64 & 0 & + & 0 \\
\hline $7 a-6-10$ & $\mathrm{M}_{\mathrm{S}} \mathrm{D}_{\mathrm{S}}$ & 8.88 & 499 & + & 0 \\
\hline $6 a-21-10$ & $\mathrm{M}_{\mathrm{R}} \mathrm{D}_{\mathrm{S}}$ & 1.31 & 0 & - & 0 \\
\hline $6 a-44-10$ & $\mathrm{M}_{\mathrm{R}} \mathrm{D}_{\mathrm{S}}$ & 3.29 & 0 & - & 0 \\
\hline $6 a-29-10$ & $\mathrm{M}_{\mathrm{R}} \mathrm{D}_{\mathrm{S}}$ & 2.09 & 0 & + & 0 \\
\hline $6 a-37-10$ & $\mathrm{M}_{\mathrm{R}} \mathrm{D}_{\mathrm{S}}$ & 4.06 & 0 & + & 0 \\
\hline $6 a-23-10$ & $\mathrm{M}_{\mathrm{S}} \mathrm{D}_{\mathrm{S}}$ & 3.96 & 0 & - & 0 \\
\hline $1 a-32-10$ & $\mathrm{M}_{\mathrm{R}} \mathrm{D}_{\mathrm{S}}$ & 11.28 & 499 & + & 0 \\
\hline $1 a-22-10$ & $\mathrm{M}_{\mathrm{S}} \mathrm{D}_{\mathrm{S}}$ & 2.55 & 499 & + & 0 \\
\hline $1 a-31-10$ & $\mathrm{M}_{\mathrm{S}} \mathrm{D}_{\mathrm{S}}$ & 5.17 & 0 & - & 0 \\
\hline $26 a-15-11$ & $\mathrm{M}_{\mathrm{S}} \mathrm{D}_{\mathrm{S}}$ & 4.53 & 224 & + & 0 \\
\hline $26 a-22-11$ & $\mathrm{M}_{\mathrm{S}} \mathrm{D}_{\mathrm{S}}$ & 1.00 & 224 & + & 0 \\
\hline $26 a-27-11$ & $\mathrm{M}_{\mathrm{S}} \mathrm{D}_{\mathrm{S}}$ & 2.49 & 0 & + & 0 \\
\hline $26 a-45-11$ & $\mathrm{M}_{\mathrm{S}} \mathrm{D}_{\mathrm{S}}$ & 2.58 & 499 & + & 0 \\
\hline $3 a-18-10$ & $\mathrm{M}_{\mathrm{S}} \mathrm{D}_{\mathrm{S}}$ & 1.19 & 0 & + & 0 \\
\hline $3 a-19-10$ & $\mathrm{M}_{\mathrm{S}} \mathrm{D}_{\mathrm{S}}$ & 1.28 & 0 & + & 0 \\
\hline $3 a-27-10$ & $\mathrm{M}_{\mathrm{S}} \mathrm{D}_{\mathrm{S}}$ & 2.81 & 0 & + & 0 \\
\hline $3 a-41-10$ & $\mathrm{M}_{\mathrm{S}} \mathrm{D}_{\mathrm{S}}$ & 1.06 & 0 & + & 0 \\
\hline $3 a-50-10$ & $\mathrm{M}_{\mathrm{S}} \mathrm{D}_{\mathrm{S}}$ & 1.32 & 0 & + & 0 \\
\hline $4 a-37-10$ & $\mathrm{M}_{\mathrm{S}} \mathrm{D}_{\mathrm{S}}$ & 2.07 & 0 & + & 0 \\
\hline $4 a-45-10$ & $\mathrm{M}_{\mathrm{S}} \mathrm{D}_{\mathrm{S}}$ & 1.34 & 193 & + & 0 \\
\hline
\end{tabular}

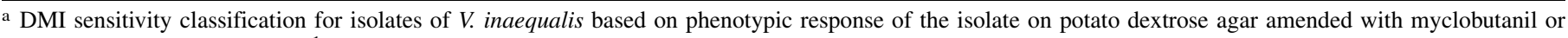
difenoconazole at $0.1 \mathrm{mg} \mathrm{ml}^{-1}$. Isolates in which mean percent relative growth $(\% \mathrm{RG})$ was $\geq 60 \%$ were characterized as resistant to myclobutanil ( $\left.\mathrm{M}_{\mathrm{R}}\right)$ or to difenoconazole $\left(\mathrm{D}_{\mathrm{R}}\right)$. Isolates with mean $\%$ RG values $<60 \%$ on myclobutanil- or difenoconazole-amended medium were characterized as sensitive $\left(\mathrm{M}_{\mathrm{S}}\right.$ or $\mathrm{D}_{\mathrm{S}}$, respectively).

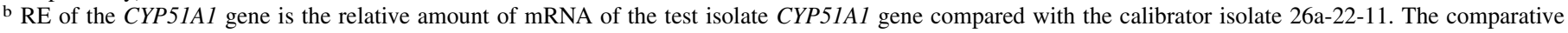
threshold cycle method was used to determine CYP51A1 expression of test isolates relative to the expression of calibrator isolate.

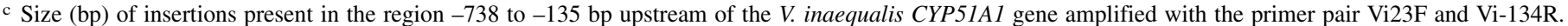

d Successful (+) or unsuccessful (-) amplification of the region -134 bp upstream of CYP51A1 using primer pair AJ468F and SV395R. 
The anticipated 604-bp fragment was amplified in 40 of the 50 $V$. inaequalis isolates and was present across all DMI sensitivity classifications. For 9 of the 50 isolates, sequence analysis of the three larger fragments revealed individual insertions of 193, 224, or $499 \mathrm{bp}$, respectively. The 224- and 499-bp insertions upstream of CYP51A were identical to those reported by Schnabel and Jones (2001). The 193-bp insert was located in a single isolate $-321 \mathrm{bp}$ upstream of the CYP51A1 gene (4a-45-11; GenBank accession number KT694304), while the 224- and 499-bp insertions were both located at position -323. In one isolate, 40b-28-11 (GenBank accession number KT694305), a 363-bp region located between positions -686 and -324 bp upstream of CYP51Al was deleted and replaced by a 352-bp sequence. This substituted region had 279 continuous nucleotides in common with the 499-bp insertion. The entire sequences of both the 193-bp insertion and the 224-bp insertion were embedded within the 499-bp insertion; however, they were disrupted by a 304-bp sequence and a 275-bp sequence, respectively, containing a predicted promoter elements (see below).

Using a cutoff score of 0.8 , two promoter elements, designated promoter element 1 (5'-AGGCCCGATTGATATATTACGCCGA GACGGCAATTCCCGTGGCAACCCGC-3'; score $=0.96$ ) and promoter element 2 (5' -ATCGTAACCATAATAAAGGCGTAGGA TTGGAAGTTTAATAAGTGGAATC-3'; score $=0.93$ ), were predicted within the 499- and 352-bp insertions. Promoter element 2 was the only promoter element predicted within the 193- and 224-bp insertions. These promoter elements were identical to those identified within the 225- and 500-bp insertions characterized previously (Schnabel and Jones 2001). The presence of either or both promoter elements in the region -738 to -135 -bp upstream of CYP51A1 did not affect expression of the CYP51A1 gene. RE of isolates with anomalies in this region ranged from 2.55 to 11.28 , whereas the RE of isolates that contained no insertions (604-bp fragment) in this upstream region ranged from 1.06 to 179.21 . In addition, the 499-bp insertion, containing promoter elements 1 and 2 , was detected in isolates that were resistant or sensitive to both DMI fungicides (Table 2).

Amplification of the region -134 bp upstream of the CYP51A1 gene using primers AJ468F and SV395R produced an 868-bp fragment in 25 of 50 isolates and a 1,051-bp fragment for a single $V$. inaequalis isolate. Sequence analysis of PCR products revealed an insertion of $183 \mathrm{bp}$ in a single isolate (1A-22-10) with an $\mathrm{M}_{S} \mathrm{D}_{\mathrm{S}}$ phenotype (GenBank accession number KT694306). The insertion was located $-65 \mathrm{bp}$ relative to the first $5^{\prime}$ adenine of CYP51A1 and contained a single promoter element ( $5^{\prime}$-GACGAAACTTAT TTATAGAAGGTCTGTGCGTAGGTGGGCCGACGTTTAGC-3') with a score of 0.94 . Upstream sequences for the other 25 isolates with the 868-bp fragment were identical sequences and no insertions were identified.

For 24 of the 50 isolates, no amplification of the region $-134 \mathrm{bp}$ upstream of the CYP51A1 gene was achieved using the AJ48F/SV395R primer set. Several other primer combinations located within $200 \mathrm{bp}$ of the AJ48F/SV395R primer sites also failed to amplify (data not shown). RE was significantly greater $(P=0.0005)$ for isolates in which amplification of the immediate upstream region was not obtained (mean $\mathrm{RE}=39.28 \pm 8.3$ ) compared with isolates in which amplification was achieved (mean $\mathrm{RE}=7.48 \pm 1.9$ ). In addition, the majority (79\%) of these isolates were characterized as resistant to difenoconazole. Within the four DMI sensitivity characterizations, no amplification of the region -134 bp upstream

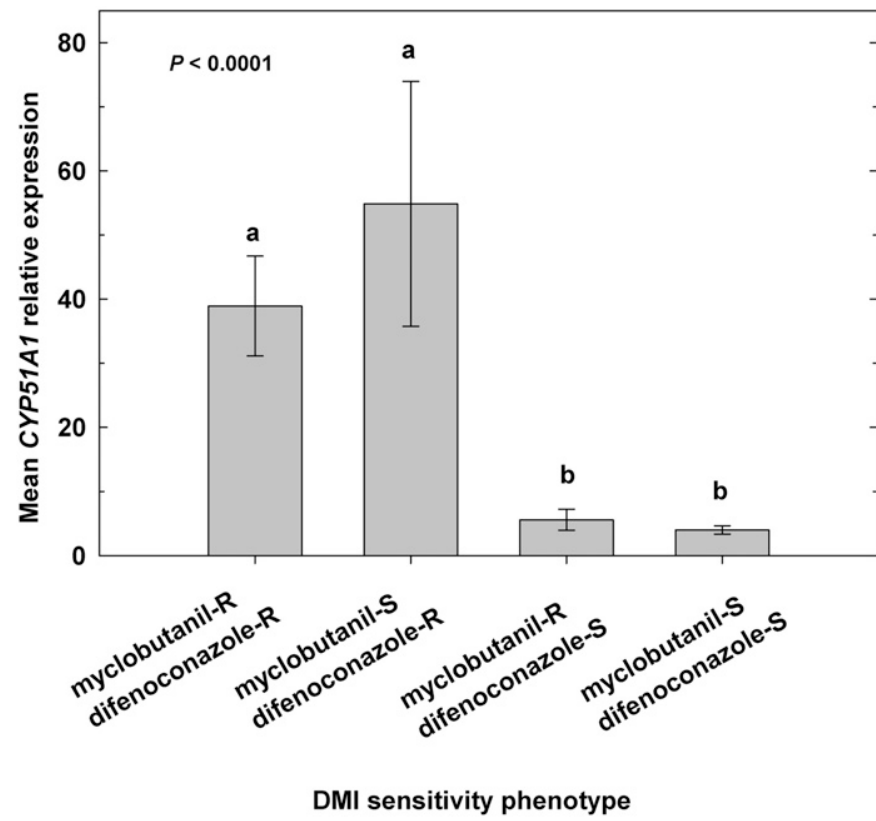

Fig. 2. Mean CYP51A1 relative expression (RE) according to demethylation inhibitor sensitivity phenotypes: myclobutanil-resistant $(\mathrm{R}) /$ difenoconazole$\mathrm{R}\left(\mathrm{M}_{\mathrm{R}} \mathrm{D}_{\mathrm{R}}, n=15\right)$, myclobutanil-sensitive $(\mathrm{S}) /$ difenoconazole- $\mathrm{R}\left(\mathrm{M}_{\mathrm{S}} \mathrm{D}_{\mathrm{R}}, n=\right.$ $8)$, myclobutanil-R/difenoconazole-S $\left(\mathrm{M}_{\mathrm{R}} \mathrm{D}_{\mathrm{S}}, n=9\right)$, and myclobutanil-S/ difenoconazole-S $\left(\mathrm{M}_{\mathrm{S}} \mathrm{D}_{\mathrm{S}}, n=18\right)$. Bars denoted by the same letter are not significantly different as denoted by the lsmeans statement of the GLIMMIX procedure in SAS v9.4 at the 5\% level of significance.
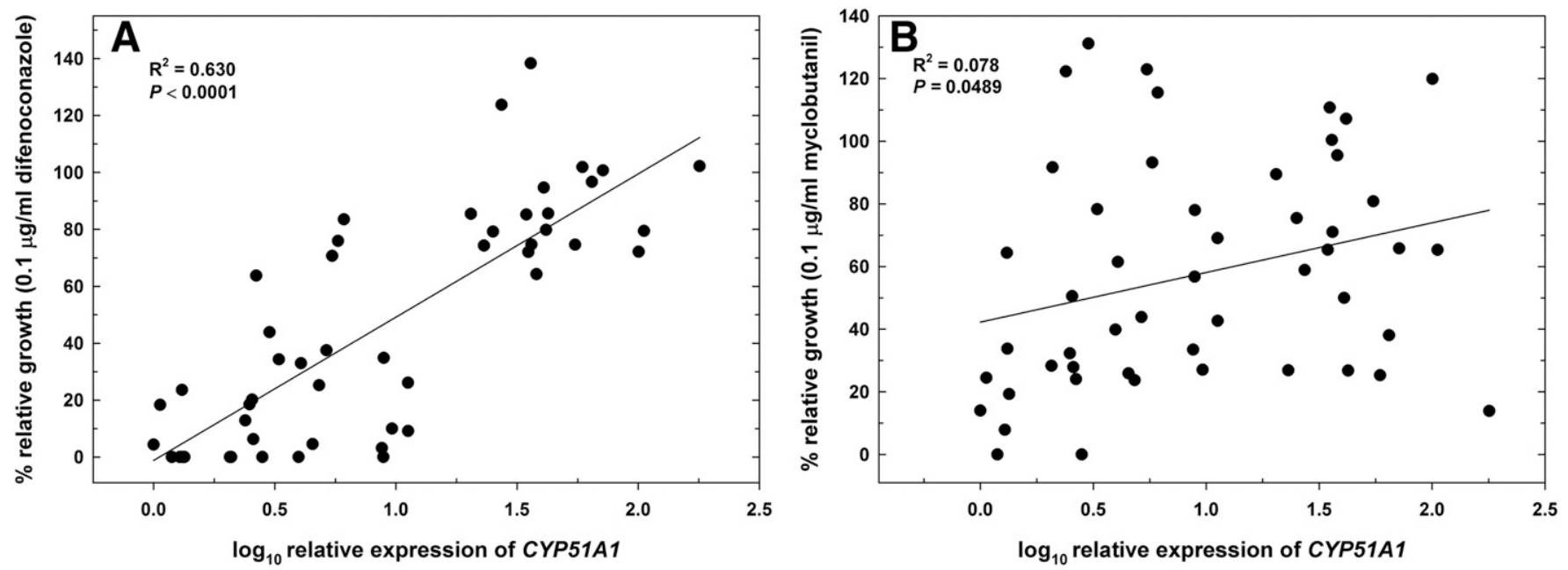

Fig. 1. $\log _{10}$ relative expression (RE) values of CYP51A1 plotted against mean percent relative growth of 50 isolates of Venturia inaequalis on A, difenoconazoleamended medium and $\mathbf{B}$, myclobutanil-amended medium at a discriminatory concentration of $0.1 \mu \mathrm{g} / \mathrm{ml}$. A linear distribution function [y $=(\mathrm{yo}+\mathrm{ax})$ ] was fitted to the $\log _{10}$ RE values of CYP51A1 and mean percent relative growth values for each respective fungicide. 
of CYP51A1 was achieved for 87 and $75 \%$ of isolates with the $M_{R} D_{R}$ or $M_{S} D_{R}$ phenotype, respectively, compared with 33 and $11 \%$ for those with the $M_{R} D_{S}$ or $M_{S} D_{S}$ phenotypes, respectively.

Illumina sequencing and bioinformatics. Illumina MiSeq sequence reads for one baseline isolate and three isolates resistant to difenoconazole yielded an average of 9 million paired-end reads of Illumina sequence data. For each isolate, an average of 10,000 contigs of approximately $300 \mathrm{bp}$ in length were assembled. To obtain maximum coverage of the CYP51A1 upstream region, genomic reads were combined and assembled for all three difenoconazole-resistant isolates. The combined assembled genome of the three difenoconazoleresistant isolates revealed that the region $-134 \mathrm{bp}$ upstream of CYP51A1 was split between two contigs. Alternatively, the region $-738 \mathrm{bp}$ upstream of CYP51A1, which had previously been sequenced for isolate 3a-27-10, was found on a single contig for the baseline isolate. Due to the number of repeated elements (see below) and presumed distance between the two upstream contigs ( $\geq 46 \mathrm{kbp}$ ), assembly of the two contigs upstream of CYP51Al could not be accomplished for the difenoconazole-resistant isolates.

In the combined genome assembly for difenoconazole-resistant isolates, a novel sequence of $474 \mathrm{bp}$ (Fig. 3) was identified upstream of $C Y P 51 A 1$ on the contig containing the CYP51Al gene (GenBank accession number KT694307). In this sequence, a unique 169-bp repeatable element, designated "EL 3,1,2", was detected 379 bp upstream from the $5^{\prime}$ end of CYP51Al and again $59 \mathrm{bp}$ downstream of the Vi-134 primer binding site (Vi-134+59 to 228) (Fig. 3). This element was not located anywhere in the genome of the baseline isolate but was repeated four times throughout the genome of isolate 40b-40-11 and twice throughout the genomes of isolates 41b-14-11 and 43b-40-11. A BLAST database search of EL 3,1,2 identified no similarity to any known sequences.

Three shorter repeated elements were identified within EL 3,1,2 and throughout the genome of the combined assembly for the three difenoconazole-resistant isolates. The first, designated "EL1", was a 42-bp sequence that was observed twice upstream of CYP51Al in EL 3,1,2 in all three resistant isolates (Fig. 3). Throughout the assembled genome sequence data, EL1 was found once in the baseline isolate and as many as six times in the assembled genome of the difenoconazole-resistant isolates. The second element, "EL2", was a 67-bp sequence found three times upstream of CYP51A1: twice in EL 3,1,2 and once by itself (Fig. 3). Throughout the assembled genomes, EL2 was found once in the baseline isolate and up to 10 times in the assembled genome of the difenoconazole-resistant isolates. Element "EL3", a 60-bp sequence, was identified four times upstream of CYP51A1 in the assembled genome of the difenoconazole-resistant isolates (Fig. 3). Throughout the assembled genomes, it was found six times in the assembled genome of the difenoconazole-resistant isolates but not found in the baseline isolate.

Based on the combined assembled genome of the three $V$. inaequalis isolates, primers were designed to verify the correct assembly of the CYP51A1 upstream region and also to detect the presence of EL 3,1,2 in isolates of $V$. inaequalis in which amplification of the region-134 bp upstream of CYP51Al was unsuccessful. Primer pair EL3,1-for/SV395R (Table 1) amplified a 907-bp fragment directly upstream of CYP51A1 that contained EL 3,1,2 (Fig. 4). To detect the presence of EL 3,1,2 in the region downstream of the Vi-134 primer binding site (Vi-134+59 to 228 ), primers Vi-185F and 7535hiup$\mathrm{R}$ (Table 1) amplified a 450-bp fragment for 17 of 23 isolates with difenoconazole resistance in which a single insertion of EL 3,1,2 was present (GenBank accession number KT694308). In two isolates, 42a-40-11 and 40b-25-11, a 957-bp fragment was produced (Fig. 4). Sequence analysis of these two isolates revealed that EL 3,1,2 was repeated in tandem four times (GenBank accession number KT694309); however, EL 3,1,2 was not present in the region directly upstream of CYP51A1 for these two isolates. EL 3,1,2 was repeated a minimum of two times upstream of CYP51A1 in 19 of $23(83 \%)$ isolates resistant to difenoconazole and was not observed in the CYP51A1 region for any isolates sensitive to difenoconazole (Table 2).

Determination of putative $C Y P 51 A 1$ transcriptional enhancers. No promoter elements with a score of 0.8 or greater were identified within EL 3,1,2. In addition, no promoter elements were detected within the 474-bp sequence (see above) characterized upstream of CYP51A1 for isolates with EL 3,1,2. Interestingly, analysis of transcription factor (TF) binding sites within $474 \mathrm{bp}$ upstream of CYP51A1 revealed differences in TF binding sites relevant to CYP51A1 expression or DMI fungicide resistance.

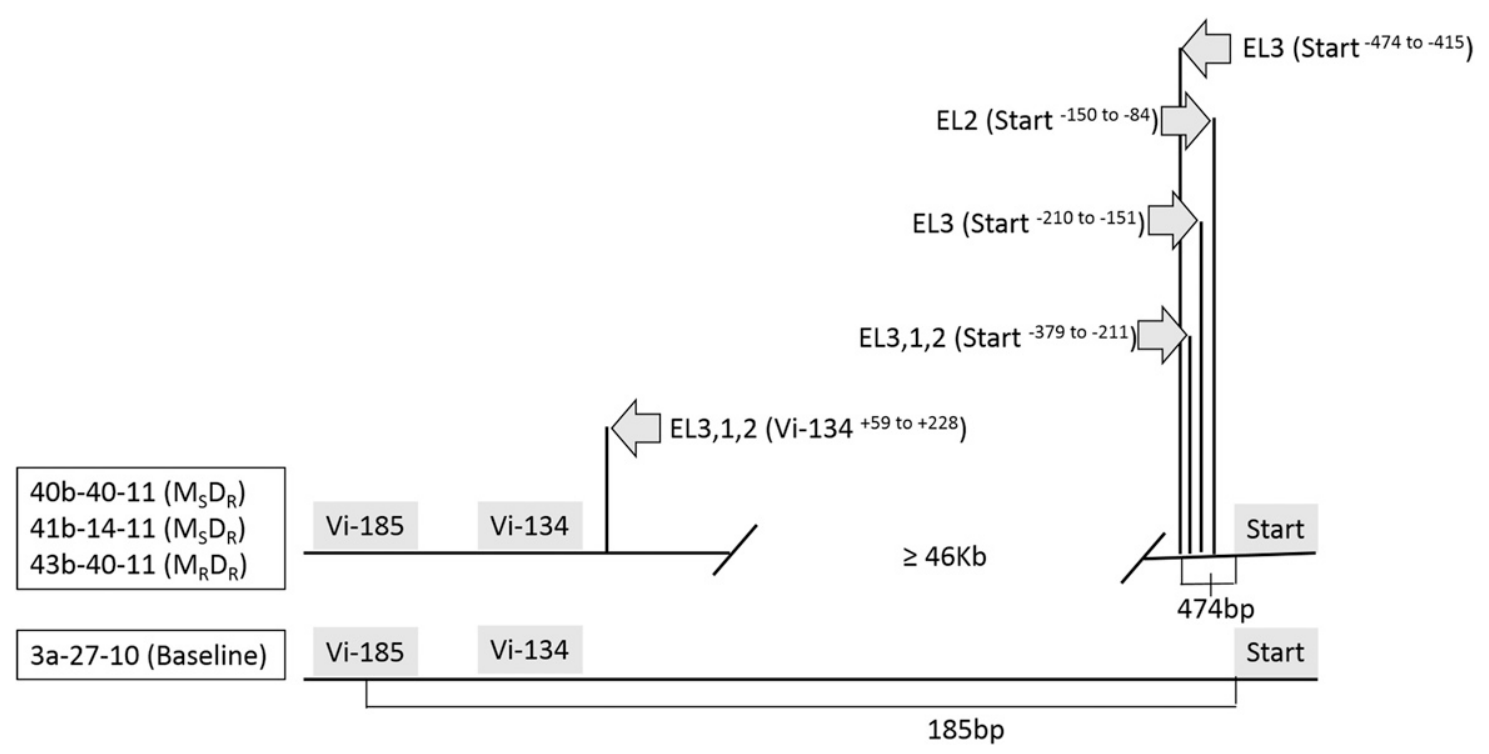

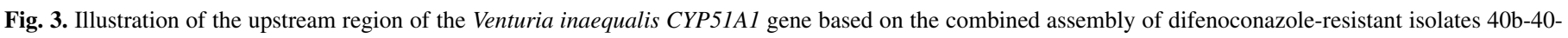

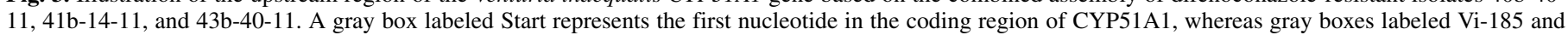

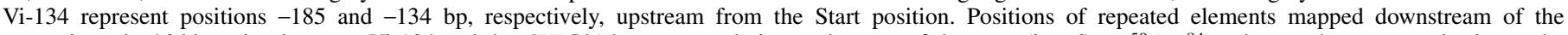

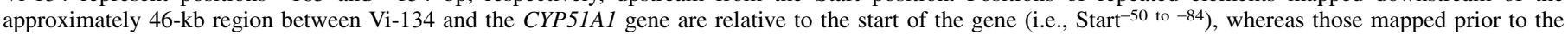

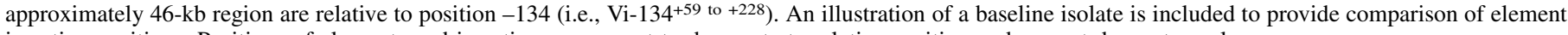
insertion positions. Positions of elements and insertions are meant to demonstrate relative position and are not drawn to scale. 
Within the 474 bp upstream of CYP51A1 for isolate 40b-40-11, there were 15 binding sites for Stb5p, a TF activator for ERG11 (CYP51A1) in yeast, compared with only 6 in the baseline isolate (3a-27-10). Additionally, isolate 40b-40-11 had fewer TF binding sites 474 bp upstream of CYP51A1 for the ergosterol biosynthesis repressor Mot3p (Montañés et al. 2011) in comparison with the baseline isolate (3a-27-10), with 3 and 5 binding sites, respectively.

\section{DISCUSSION}

Sterol DMI fungicides target the $14 \alpha$-demethylase enzyme, an essential precursor to ergosterol biosynthesis encoded by the CYP51A1 gene. Resistance to DMIs has been attributed to a number of mechanisms, including amino acid alterations in the target enzyme, overexpression of genes encoding drug efflux pumps, and overexpression of the CYP51Al gene. Although several studies have previously focused on elucidating the molecular mechanisms of resistance for a single DMI fungicide (Cools et al. 2013), in the present study, we found that several regulatory elements associated with resistance to difenoconazole were not present in isolates of $V$. inaequalis with resistance to myclobutanil. To our knowledge, this is the first report of a plant pathogen exhibiting differential resistance to two triazole DMI fungicides in a single isolate.

Overexpression of the CYP51A1 gene has been implicated in DMI fungicide resistance for several phytopathogenic fungi, including Penicillium digitatum (Hamamoto et al. 2000; Sun et al. 2013), Blumeriella jaapii (Ma et al. 2006), Monilinia fructicola (Luo and Schnabel 2008), Puccinia triticina (Stammler et al. 2009), and Mycospharella graminicola (Cools et al. 2010). In this study, $\mathrm{RE}$ of CYP51A1 was evaluated for 50 isolates of $V$. inaequalis exhibiting varying levels of sensitivity to difenoconazole and myclobutanil. Isolates resistant to difenoconazole (those with the $\mathrm{M}_{\mathrm{R}} \mathrm{D}_{\mathrm{R}}$ and $\mathrm{M}_{\mathrm{S}} \mathrm{D}_{\mathrm{R}}$ phenotype) had a 9-fold increase in CYP51A1 RE compared with isolates with an $\mathrm{M}_{\mathrm{R}} \mathrm{D}_{\mathrm{S}}$ phenotype and a 13-fold increase in $R E$ compared with isolates an $\mathrm{M}_{S} \mathrm{D}_{\mathrm{S}}$ phenotype. This level of expression was similar to other phytopathogenic fungi resistant to DMI fungicides, where expression values were observed to be more than fivefold greater when target gene overexpression was the primary mechanism of resistance (Hamamoto et al. 2000; Luo and Schnabel 2008; Ma et al. 2006).

CYP51A1 overexpression and subsequent DMI fungicide resistance can result from a number of factors, including duplication of the CYP51 gene, insertions of DNA-containing promoter elements or transcriptional enhancers upstream of $C Y P 51$, and single nucleotide polymorphisms within the coding region of the gene. In the human pathogen Candida glabrata (Marichal et al. 1997) and the plant pathogen Fusarium graminearum (Liu et al. 2011), multiple copies of CYP51 were found to be the driving force of target gene overexpression. In this study, genomic sequencing of a baseline isolate and of three difenoconazole-resistant isolates found no paralogous CYP51 genes. However, a unique 169-bp repeatable element upstream of CYP51A1 was identified. This element, EL 3,1,2, was repeated two to four times upstream of CYP51A1 in $83 \%$ of difenoconazole-resistant isolates but not in isolates sensitive to difenoconazole.

Although EL 3,1,2 is highly associated with difenoconazole resistance and CYP51A1 overexpression, the repeatable element was not found in the upstream region of CYP51A1 for two isolates with $M_{S} D_{R}$ phenotypes and for two isolates with $M_{R} D_{R}$ phenotypes. The absence of EL 3,1,2 in these four isolates further illustrates the complexity of DMI fungicide resistance in $V$. inaequalis because resistance to DMIs not only may be governed by different mechanisms but also the molecular basis of resistance may differ between isolates as well. For example, in myclobutanil-resistant isolates from Michigan, the presence of a 553-bp insertion upstream of CYP51Al was linked to overexpression of the $V$. inaequalis CYP51A1 gene (Schnabel and Jones 2001). However, this insertion was only present in $23 \%$ of myclobutanil-resistant isolates and in isolates with a CYP51A1 RE value of 5.0 or greater. Furthermore, we previously identified the 553-bp insertion in two DMI-sensitive isolates of $V$. inaequalis from Virginia (Cox et al. 2008). In the present study, the correlation of EL 3,1,2 and difenoconazole resistance was more prevalent in isolates with overexpression of CYP51A1 (Schnabel and Jones 2001), being identified in the majority (83\%) of isolates with difenoconazole resistance.

The presence of EL 3,1,2 solely in isolates with difenoconazole resistance strongly supports its association with resistance to difenoconazole and as a driving factor of CYP51Al overexpression. Similar relationships between repeated elements in the upstream region of $C Y P 51 A 1$ and overexpression of the gene have previously been characterized. In Penicillium digitatum, a 126-bp element acting as a transcriptional enhancer was tandemly repeated five times upstream of CYP51 in DMI-resistant strains and only once in DMI-sensitive strains. Although no promoter elements were predicted within the 126-bp tandem repeat, it was suggested that the presence of known fungal and vertebrate TF binding sites within the sequence might serve as a mechanism for CYP51 transcriptional enhancement (Hamamoto et al. 2000).

Similar to the 126-bp tandemly repeated element found in $P$. digitatum, TF binding sites but no predicted promoter elements were found in El 3,1,2. Although there were only $15 \mathrm{TF}$ binding sites present, 8 had the capacity to bind the transcriptional enhancer zinc cluster protein TF Stb5p. Like many zinc cluster proteins (MacPherson et al. 2006; Rank et al. 1975; Saunders and Rank 1982; Wehrschütz-Sigl et al. 2004), Stb5p has been implicated as a positive regulator of multidrug resistance genes and also as a direct activator of ERG11 (CYP51A1) (Larochelle et al. 2006; MacPherson et al. 2006) in yeast. The introduction of eight Stb5p binding sites within each EL 3,1,2 insertion upstream of CYP51A1 may have contributed to the observed higher CYP51Al expression values in difenoconazole-resistant $V$. inaequalis isolates. Due to the paucity of predicted promoter elements in the upstream region of $C Y P 51 A 1$, we also searched for TF binding sites $474 \mathrm{bp}$ upstream of the first $5^{\prime}$ adenine of CYP51A1 for both baseline isolate 3a-27-10 and $\mathrm{M}_{S} \mathrm{D}_{\mathrm{R}}$ isolate 40b-40-11. Compared with the baseline isolate, which had 6 Stb5p binding sites within the queried region, 15 Stb5p binding sites

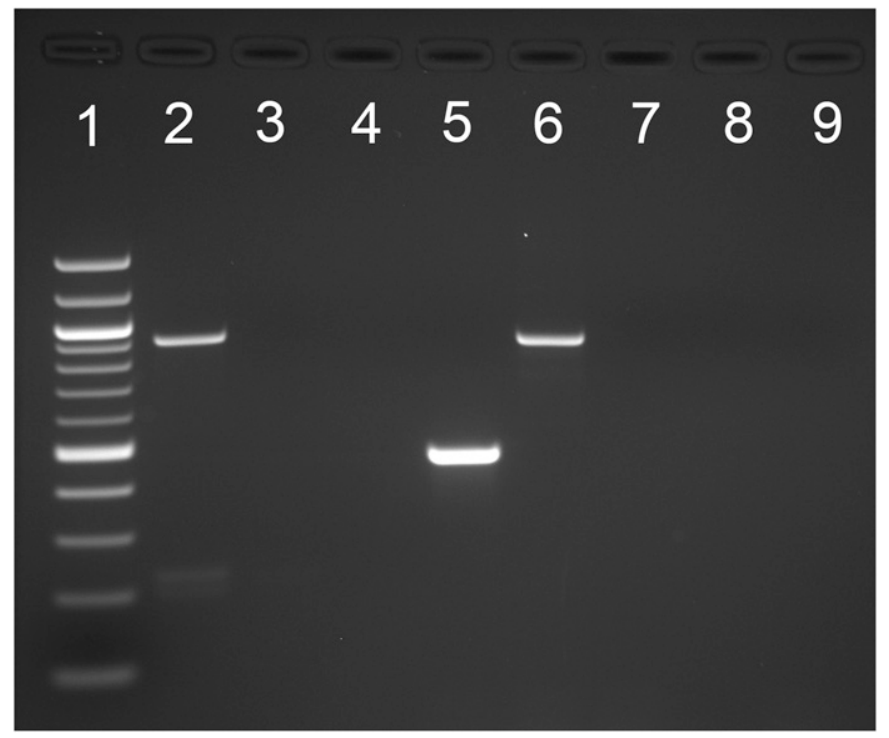

Fig. 4. Amplification of a 907-bp fragment containing EL 3,1,2 in the region directly upstream of CYP51A1 (lanes 2 to 5 and 8, primers EL3,1-for/SV395R) or a 450- or 957-bp fragment containing EL 3,1,2 at downstream of position Vi-134+59 to 228 (lanes 5 to 7 and 9, primers Vi-185F/7535hiup-R). EL 3,1,2 was repeated in tandem four times in isolates that produced the 957-bp fragment. Lane 1, Quick-Load 100-bp DNA Ladder (New England Bio-Labs); lanes 2 and 5, isolate 38b-24-11; lanes 3 and 6, isolate 40b-25-11; lanes 4 and 7, isolate 1a-31-10; lanes 8 and 9, nontemplate control. 
were identified for the difenoconazole-resistant isolate, which included the 8 from El 3,1,2.

Two additional binding sites for the TF Mot3p were confirmed in the CYP51A1 upstream region of the baseline isolate compared with the difenoconazole-resistant isolate. Unlike Stb5p, Mot3p represses the transcription of ergosterol biosynthesis genes (Montañés et al. 2011). The presence of these two transcription regulators, which appear to function antagonistically, raises questions regarding the importance of their ratio (Kim and Forger 2012) in CYP51Al expression and subsequent difenoconazole resistance. In baseline isolates, the ratio of Mot3p (repressor) to Stb5p (activator) was 5:7, compared with 3:15 in the difenoconazole-resistant isolates. Thus, it may not simply be the introduction of Stb5p binding sites into the immediate upstream region of CYP51A1 but also the lower ratio of the TF repressing ergosterol biosynthesis.

The absence of EL 3,1,2 and the relatively low levels of CYP51A1 $R E$ in isolates of $V$. inaequalis with the $M_{R} D_{S}$ phenotype suggests that the molecular basis of resistance may be different between myclobutanil and difenoconazole. Indeed, mean relative CYP51A1 expression for isolates of $V$. inaequalis with resistance to myclobutanil only $\left(\mathrm{M}_{\mathrm{R}} \mathrm{D}_{\mathrm{S}}\right)$ was not significantly different $(P>0.05)$ than isolates exhibiting the $\mathrm{M}_{S} \mathrm{D}_{\mathrm{S}}$ phenotype, indicating that the contribution of target gene overexpression in myclobutanil resistance may be minor. Regression analysis of isolate \%RG on myclobutanil- or difenoconazole-amended medium and $\log _{10} C Y P 51 A 1 \mathrm{RE}$ values further supported the observation that $C Y P 51 A 1$ overexpression was not a primary genetic determinant of resistance to myclobutanil. Indeed, a similar relationship was observed for propiconazoleresistant isolates of Sclerotinia homoeocarpa and the S. homoeocarpa efflux transporter, ShatrD, which led to the conclusion that ShatrD overexpression and not CYP51 overexpression was the driving force behind propiconazole resistance in that pathosystem (Hulvey et al. 2012). The low levels of CYP51A1 expression for isolates with $M_{R} D_{S}$ phenotypes in this study are in stark contrast to CYP51A1 expression values for myclobutanil-resistant isolates of $V$. inaequalis from Michigan, which had an 18-fold increase in CYP51A1 RE (Schnabel and Jones 2001). Although it is difficult to speculate regarding the reasons for this discrepancy between the two studies, it is not beyond the realm of possibility that the isolates screened in the 2001 study could have had a multiple DMI resistance phenotype that was mediated by overexpression of the target gene.

Resistance to DMI fungicides has also been conferred in fungi by the presence of point mutations leading to a change in the amino acid sequence of CYP51A1 (Becher and Wirsel 2012; Délye et al. 1997; Gadoury et al. 2012; Wyand and Brown 2005). Depending on the location of an amino acid substitution, the binding affinity of DMI fungicides can be significantly reduced. Unlike the target genes of QoI fungicides, where amino acid substitutions are generally conserved across all fungal genera (Fernández-Ortuño et al. 2008), CYP51 point mutations conferring DMI resistance are not frequently conserved in phytopathogenic fungi (Becher and Wirsel 2012; Cools et al. 2013). Upon verifying the predicted CYP51Al amino acid sequence (Schnabel and Jones 2001), we found no alterations within the coding sequence among any of the isolates or any of the mutations that have previously been associated with DMI resistance in other phytopathogens (Cools et el. 2013).

Overall, the results of this study have shown that the CYP51A1 gene is overexpressed in isolates of $V$. inaequalis with practical resistance to difenoconazole $\left(\mathrm{M}_{\mathrm{S}} \mathrm{D}_{\mathrm{R}}\right)$ or difenoconazole and myclobutanil $\left(\mathrm{M}_{\mathrm{R}} \mathrm{D}_{\mathrm{R}}\right)$ but not in the majority of isolates with practical resistance to myclobutanil only. This finding suggests that resistance between myclobutanil and difenoconazole may develop independently and helps to explain the apparent lack of cross-sensitivity in several isolates with practical resistance to myclobutanil. The extent that overexpression of CYP51A1 contributes to resistance of other DMI fungicides in $V$. inaequalis is still undetermined. Although we were unable to elucidate the mechanism of myclobutanil resistance, the involvement of overexpressed genes encoding drug efflux transporters (Hayashi et al. 2002; Hulvey et al. 2012; Nakaune et al. 1998) has yet to be evaluated for V. inaequalis. Identification and expression analysis of undiscovered drug efflux pumps and the mechanisms promoting their overexpression not only might provide explanation for myclobutanil resistance in $V$. inaequalis but also could provide insight into multiple-fungicide resistance for this pathogen.

\section{ACKNOWLEDGMENTS}

This work was supported, in part, by funds appropriated to New York State Agricultural Experiment Station, Cornell University. We thank $\mathrm{J}$. Frier for her assistance in conducting RT-qPCR for CYP51A1 expression analysis; and A. Biggs, G. Koehler, J. Raes, and C. Lehman for their assistance in the collection, preparation, and evaluation of isolates in several over the years.

\section{LITERATURE CITED}

Asai, K., Tsuchimori, N., Okonogi, K., Perfect, J. R., Gotoh, O., and Yoshida, Y. 1999. Formation of azole-resistant Candida albicans by mutation of sterol 14-demethylase P450. Antimicrob. Agents Chemother. 14:1163-1169.

Becher, R., and Wirsel, S. G. R. 2012. Fungal cytochrome P450 sterol $14 \alpha$-demethylase (CYP51) and azole resistance in plant and human pathogens. Appl. Environ. Microbiol. 95:825-840.

Beckerman, J. L., Sundin, G. W., and Rosenberger, D. A. 2015. Do some IPM concepts contribute to the development of fungicide resistance? Lessons learned from the apple scab pathosystem in the United States. Pest Manage. Sci. 71:331-342.

Braun, P. G., and McRae, K. B. 1992. Composition of a population of Venturia inaequalis resistant to myclobutanil. Can. J. Plant Pathol. 14:215-220.

Cools, H. J., Hawkins, N. J., and Fraaije, B. A. 2013. Constraints on the evolution of azole resistance in plant pathogenic fungi. Plant Pathol. 62: 36-42.

Cools, H. J., Parker, J. E., Kelly, D. E., Lucas, J. A., Fraaije, B. A., and Kelly, S. L. 2010. Heterologous expression of mutated eburicol 14a-demethylase (CYP51) proteins of Mycosphaerella graminicola to assess effects on azole fungicide sensitivity and intrinsic protein function. Appl. Environ. Microbiol. 76:2866-2872.

Cox, K. D., Russo, N. L., Villani, S. M., Parker, D. M., and Köller, W. 2008. QoI qualitative resistance and CYP51A1 upstream anomalies in NY populations of the apple scab pathogen Venturia inaequalis. (Abstr.) Phytopathology 98:S42.

Délye, C., Laigre, F., and Corio-Costet, M. F. 1997. A mutation in the $14 \alpha$-demethylase gene of Uncinula necator that correlates with resistance to a sterol biosynthesis inhibitor. Appl. Environ. Microbiol. 63:2966-2970.

Fernández-Ortuño, D., Torés, J. A., de Vicente, A., and Pérez-García, A. 2008. Mechanisms of resistance to QoI fungicides in phytopathogenic fungi. Int. Microbiol. 11:1-9.

Frederick, Z. A., Villani, S. M., Cooley, D. R., Biggs, A. R., Raes, J. J., and Cox, K. D. 2014. Prevalence and stability of qualitative QoI resistance in populations of Venturia inaequalis in the northeastern United States. Plant Dis. 98:1122-1130.

Gadoury, D. M., Cadle-Davidson, L., Wilcox, W. F., Dry, I. B., Seem, R. C., and Milgroom, M. G. 2012. Grapevine powdery mildew (Erysiphe necator): A fascinating system for the study of the biology, ecology and epidemiology of an obligate biotroph. Mol. Plant Pathol. 13:1-16.

Hamamoto, H., Hasegawa, K., Nakaune, R., Young, J. L., Makizumi, Y., Akutsu, K., and Hibi, T. 2000. Tandem repeat of a transcriptional enhancer upstream of the sterol $14 \alpha$-demethylase gene (CYP51) in Penicillium digitatum. Appl. Environ. Microbiol. 66:3421-3426.

Hawkins, N., Cools, H. J., Shaw, M. W., Sierotzki, H., and Fraaije, B. A. 2011. Molecular mechanisms of altered fungicide sensitivity in Rhynchosporium secalis. Pages 129-134 in: Modern Fungicides and Antifungal Compounds VI: Proc. 16th Int. Reinhardsbrunn Symp. Modern Fungicides and Antifungal Compounds. H. W. Dehne, H. B. Deising, U. Gisi, K. H. Kuck, P. E. Russell, and H. Lyr, eds.

Hayashi, K., Schoonbeek, H. J., and De Waard, M. A. 2002. Expression of the $\mathrm{ABC}$ transporter BcatrD from Botrytis cinerea reduces sensitivity to sterol demethylation inhibitor fungicides. Pestic. Biochem. Physiol. 73:110-121.

Hildebrand, P. D., Lockhart, C. L., Newbery, R. J., and Ross, R. G. 1988. Resistance of Venturia inaequalis to bitertanol and other demethylationinhibiting fungicides. Can. J. Plant Pathol. 10:311-316.

Hsiang, T., Yang, L., and Barton, W. 1997. Baseline sensitivity and crossresistance to demethylation-inhibiting fungicides in Ontario isolates of Sclerotinia homoeocarpa. Eur. J. Plant Pathol. 103:409-416. 
Hulvey, J., Popko, J. T., Sang, H., Berg, A., and Jung, G. 2012. Overexpression of ShCYP51B and ShatrD in Sclerotinia homoeocarpa isolates exhibiting practical field resistance to a demethylation inhibitor fungicide. Appl. Environ. Microbiol. 78:6674-6682.

Jobin, T., and Carisse, O. 2007. Incidence of myclobutanil- and kresoximmethyl-insensitive isolates of Venturia inaequalis in Quebec orchards. Plant Dis. 91:1351-1358.

Karaoglanidis, G. S., and Thanassoulopoulos, C. C. 2003. Cross-resistance patterns among sterol biosynthesis inhibiting fungicides (SBIs) in Cercospora beticola. Eur. J. Plant Pathol. 109:929-934.

Kim, J. K., and Forger, D. 2012. A mechanism for robust circadian timekeeping via stoichiometric balance. Mol. Syst. Biol. 8:1-14.

Köller, W., Parker, D. M., Turechek, W. W., Avila-Adame, C., and Cronshaw, K. 2004. A two-phase resistance response of Venturia inaequalis populations to the QoI fungicides kresoxim-methyl and trifloxystrobin. Plant Dis. 88:537-544.

Köller, W., and Scheinpflug, H. 1987. Fungal resistance to sterol biosynthesis inhibitors: A new challenge. Plant Dis. 71:1066-1074.

Köller, W., and Wilcox, W. F. 1999. Evaluation of tactics for managing resistance of Venturia inaequalis to sterol demethylation inhibitors. Plant Dis. $83: 857-863$

Köller, W., and Wilcox, W. F. 2001. Evidence for the predisposition of fungicide- resistant phenotypes of Venturia inaequalis to a preferential selection for resistance to other fungicides. Phytopathology 91:776781.

Köller, W., Wilcox, W. F., Barnard, J., Jones, A. L., and Braun, P. G. 1997. Detection and quantification of resistance of Venturia inaequalis populations to sterol demethylation inhibitors. Phytopathology 87:184-190.

Larochelle, M., Drouin, S., Robert, F., and Turcotte, B. 2006. Oxidative stressactivated zinc cluster protein Stb5 has dual activator/repressor functions required for pentose phosphate pathway regulation and NADPH production. Mol. Cell. Biol. 26:6690-6701.

Lesniak, K. E., Proffer, T. J., Beckerman, J. L., and Sundin, G. W. 2011. Occurrence of QoI resistance and detection of the G143A mutation in Michigan populations of Venturia inaequalis. Plant Dis. 95:927-934.

Liu, X., Yu, F., Schnabel, G., Wu, J., Wang, Z., and Ma, Z. 2011. Paralogous cyp51 genes in Fusarium graminearum mediate differential sensitivity to sterol demethylation inhibitors. Fungal Genet. Biol. 48:113-123.

Liu, X. N., and Baird, W. V. 2001. Rapid amplification of genomic ends NIaIII partial digestion and polynucleotide tailing. Plant Mol. Biol. Rep. 19:261-267.

Livak, K. J., and Schmittgen, T. D. 2001. Analysis of relative gene expression data using real-time quantitative PCR and the $2^{-\triangle \Delta C T}$ method. Methods 25: 402-408.

Luo, C. X., and Schnabel, G. 2008. The cytochrome P450 Lanosterol 14 $\alpha$ demethylase gene is a demethylation inhibitor fungicide resistance determinant in Monilinia fructicola field isolates from Georgia. Appl. Environ. Microbiol. 74:359-366.

Lupetti, A., Danesi, R., Campa, M., Del Tacca, M., and Kelly, S. 2002. Molecular basis of resistance to azole antifungals. Trends Mol. Med. 8:76-81.

Ma, Z., Proffer, T. J., Jacobs, J. L., and Sundin, G. W. 2006. Overexpression of the $14 \alpha$-demethylase gene (CYP51) mediates fungicide resistance in Blumeriella jaapii. Appl. Environ. Microbiol. 72:2581-2585.

MacHardy, W. E. 1996. Apple Scab-Biology, Epidemiology, and Management. American Phytopathological Society, St. Paul, MN.

MacHardy, W. E., Gadoury, D. M., and Gessler, C. 2001. Parasitic and biological fitness of Venturia inaequalis: Relationship to disease management strategies. Phytopathology 85:1036-1051.
MacPherson, S., Larochelle, M., and Turcotte, B. 2006. A fungal family of transcriptional regulators: The zinc cluster proteins. Microbiol. Mol. Biol. Rev. 70:583-604.

Marichal, P., Vanden Bossche, H. V., Odds, F. C., Nobels, G., Warnock, D. W., Timmerman, V., Van Broeckhoven, C., Fay, S., and Mose-Larsen, P. 1997. Molecular biological characterization of an azole-resistant Candida glabrata isolate. Antimicrob. Agents. 41:2229-2237.

Montañés, F. M., Pascual-Ahuir, A., and Proft, M. 2011. Repression of ergosterol biosynthesis is essential for stress resistance and is mediated by the Hog1 MAP kinase and the Mot3 and Rox1 transcription factors. Mol. Microbiol. 79:1008-1023.

Nakaune, R., Adachi, K., Nawata, O., Tomiyama, M., Akutsu, K., and Hibi, T. 1998. A novel ATP-binding cassette transporter involved in multidrug resistance in phytopathogenic fungus Penicillium digitatum. Appl. Environ. Microbiol. 64:3983-3988.

Rank, G. H., Robertson, A. J., and Phillips, K. L. 1975. Modification and inheritance of pleiotropic cross resistance and collateral sensitivity in Saccharomyces cerevisiae. Genetics 80:483-493.

Saunders, G. W., and Rank, G. H. 1982. Allelism of pleiotropic drug resistance in Saccharomyces cerevisiae. Can. J. Genet. Cytol. 24:493-503.

Schnabel, G., and Jones, A. L. 2001. The 14 $\alpha$-Demethylase (CYP51A1) gene is overexpressed in Venturia inaequalis strains resistant to myclobutanil. Phytopathology 91:102-110.

Smith, F. D., Parker, D. M., and Köller, W. 1991. Sensitivity distribution of Venturia inaequalis to the sterol demethylation inhibitor flusilazole: Baseline sensitivity and implications for resistance monitoring. Phytopathology 81:392-396.

Stammler, G., Cordero, J., Koch, A., Semar, M., and Schlehuber, S. 2009. Role of the Y134F mutation in cyp51 and overexpression of cyp51 in the sensitivity response of Puccinia triticina to epoxiconazole. Crop Prot. 28: 891-897.

Sun, X., Xu, Q., Ruan, R., Zhang, T., Zhu, C., and Li, H. 2013. PdMLE1, a specific and active transposon acts as a promoter and confers Penicillium digitatum with DMI resistance. Environ. Microbiol. Rep. 5: 135-142.

Szkolnik, M. 1981. Physical modes of action of sterol-inhibiting fungicides against apple diseases. Plant Dis. 65:981-985.

Villani, S. M., Biggs, A. R., Cooley, D. R., Raes, J. J., and Cox, K. D. 2015. Prevalence of myclobutanil resistance and difenoconazole insensitivity in populations of Venturia inaequalis. Plant Dis. 99: 1526-1536.

Villani, S. M., and Cox, K. D. 2011. Characterizing fenbuconazole and propiconazole sensitivity and prevalence of 'Mona' in isolates of Monilinia fructicola from New York. Plant Dis. 95:828-834.

Wehrschütz-Sigl, E., Jungwirth, H., Bergler, H., and Hogenauer, G. 2004. The transporters Pdr5p and Snq2 $p$ mediate diazaborine resistance and are under the control of the gain-of-function allele PDR1-12. Eur. J. Biochem. 271: $1145-1152$.

Wyand, R. A., and Brown, J. K. M. 2005. Sequence variation in the CYP51 gene of Blumeria graminis associated with resistance to sterol demethylase inhibiting fungicides. Fungal Genet. Biol. 42:726-735.

Yoder, K. S. 2000. Effect of powdery mildew on apple yield and economic benefits of its management in Virginia. Plant Dis. 84:1171-1176.

Yoder, K. S., Cochran, A. E., II, Royston, W. S., Jr., Kilmer, S. W., Engelman, A. G. F., and Hickey, L. A. 2014. Disease control by experimental and registered fungicides and mixtures on Golden Delicious, Idared, and York Imperial apples, 2013. Online publication. Plant Dis. Manage. Rep. 8: PF018. doi:10.1094/PDMR08 